Revue bibliographique pour le domaine irano-aryen

\title{
Michael Jursa. "Judeans and other West Semites: Another View from the Babylonian Countryside"
}

\section{Benjamin Dromard}

\section{(2) OpenEdition}

1 Journals

\section{Édition électronique}

URL : https://journals.openedition.org/abstractairanica/52779

DOI : 10.4000/abstractairanica.52779

ISSN : 1961-960X

Éditeur :

CNRS (UMR 7528 Mondes iraniens et indiens), Éditions de l'IFRI

\section{Référence électronique}

Benjamin Dromard, « Michael Jursa. "Judeans and other West Semites: Another View from the Babylonian Countryside" », Abstracta Iranica [En ligne], Volume 42-43 | 2021, document 40, mis en ligne le 30 juillet 2021, consulté le 14 décembre 2022. URL : http://journals.openedition.org/ abstractairanica/52779; DOI : https://doi.org/10.4000/abstractairanica.52779

Ce document a été généré automatiquement le 14 décembre 2022.

Tous droits réservés 


\title{
Michael Jursa. "Judeans and other West Semites: Another View from the Babylonian Countryside"
}

\author{
Benjamin Dromard
}

\section{RÉFÉRENCE}

Michael Jursa. "Judeans and other West Semites: Another View from the Babylonian Countryside", Hebrew Bible and Ancient Israel 9/1, 2020, p. 20-40.

1 La présence de Judéens et de populations ouest-sémitiques en Babylonie est de mieux en mieux attestée, que ce soit dans des zones rurales comme dans certaines villes (Babylone, Sippar, Kiš et Nippur). Cela demeure toutefois plus difficile pour ce qui concerne le sud de la Babylonie et notamment la ville d'Uruk. Michael Jursa prend comme point de départ de son article le texte YBC 4022 (édité), une liste d'individus livrant des quantités de dattes. La tablette est conservée dans la collection de l'université de Yale, qui contient essentiellement des documents provenant de l'archive de l'Eanna d'Uruk. Il ne s'agit pas de paiements de loyers pour des palmeraies, comme il est plus souvent coutume. Les quantités sont trop faibles en comparaison du reste de la documentation. Il semble plutôt s'agir de paiements de dîmes auprès du temple. 51 anthroponymes sont mentionnés dans ce document, et la plupart des personnes identifiables portent des noms ou des patronymes ouest-sémitiques (arabes, araméens, judéens). L'auteur présente chacun des noms afin de bien en retracer les origines et d'en établir la traduction. Certains individus mentionnés sont Babyloniens et peuvent être identifiés dans d'autres documents (PTS 2752, édité).

2 En annexes, on trouve tout d'abord l'édition du texte SMUI 1913.14.1577, listant 12 responsables tribaux de Bït-Awkānu devant des obligations envers l'Eanna d'Uruk. 4 portent un nom araméen, le reste portant un nom akkadien. Cela donne là aussi une 
idée de la composition socio-ethnique dans la région d'Uruk. La deuxième annexe est un index des noms mentionnés dans l'article.

\section{AUTEURS}

\section{BENJAMIN DROMARD}

Université Paris 1 Panthéon Sorbonne 